\title{
Median and Maximum Frequency Analysis of Vibration Signals on Human Face
}

\author{
Mehmet Umit AK ${ }^{1}$, Suleyman BILGIN ${ }^{2}$, , Okan ORAL ${ }^{3}$, Egehan CETIN ${ }^{1}$, H. Feza \\ CARLAK ${ }^{2}$, Alper Tunga DERIN ${ }^{4}$, Narin DERIN ${ }^{5}$
}

\begin{abstract}
1Department of Electrical \& Electronics Engineering, Institute of Natural Sciences, Akdeniz University, Turkey 2Department of Electrical \& Electronics Engineering, Faculty of Engineering, Akdeniz University, Turkey 3Department of Mechatronic Engineering, Faculty of Engineering, Akdeniz University, Antalya, Turkey 4 Department of Surgical Medical Sciences, Faculty of Medicine, Akdeniz University, Antalya, Turkey 5 Department of Basic Medical Sciences, Faculty of Medicine, Akdeniz University, Antalya, Turkey

*Corresponding author
\end{abstract}

\begin{abstract}
.
There are some studies in the literature in order to make the interpretation of human tissues having different characteristics. Some of these studies focused on the evaluation of human face tissues. Vibration signals generated from vocal cords have been used in these studies about human face tissues. However, any study using the vibration signals recorded by applying the external vibration source having fixed frequency value is not available in the literature. In this study, it is aimed to investigate the frequency characteristics of the vibration signals recorded from human face. These signals obtained from 9 different regions on the faces of subjects are analysed using frequency characteristics. In the analysis stage, median and maximum frequency values are calculated and evaluated. So, the softness and hardness interpretation about these regions on the face can be made and the frequency ranges of these regions can be determined. As a result, it is observed that low frequency signals are dominant in hard regions and high frequency signals are dominant in soft regions.
\end{abstract}

Keywords: human tissue, vibration signal, accelerometer, signal processing 


\title{
International Conference on Research in ENGINEERING
} and TECHNOLOGY

\section{2-14 December, 2019}

\author{
Barcelona, spain
}

\section{Introduction}

It is known that human tissues show different characteristics and various studies have been carried out to interpret these differences. In these studies, vibration signals recorded from human tissues are used and proposed solutions that can help in the detection of various types of disease. Coyte et al. realized a study on whole-body vibration analysis technologies and modelling. This study provides a literature review of topics including recent researches about vibration signal processing and modelling of the bio-dynamic response of the human sitting to vibrations (Coyte et al., 2015). It is also possible to explain the effects of vibration sources on different human tissues (Peter et al, 1987), (Zhang et al.,2009), (Yanxi \& Qingxia, 2010), (Kitamura, 2010). Balbinot et al. realized the development of a system integrated with the ZigBee network to measure human vibration. The developed system allows the separation of human vibrations of approximately $40 \mathrm{~Hz}$ on 3-axes. They explained that vibration in workers working on machines such as tractors and diggers can contribute to the occurrence of back pain (Balbinot et al., 2008), (De Capua et al., 2009). Amar et al. tried to explain the damping properties of the human body as spring and damper system against vibrations applied to human tissue. The main purpose of the study is to reveal the damping properties of human tissue and to extract the spring and damping constants of the system (Amar, 2010). Vibration signal analysis has been included in research on the human face as well as on the human body. In these researches, the analyses have focused on the vibration signals that are usually occurred in the vocal cords during the talking (Morillo et al., 2010), (Chen et al., 2014), (Orun, 2017), (Kitamura et al., 2013). However, these studies are realized using vibration signals having frequencies that exhibit variation depending on the vocal cords. However, the vibration signals obtained by applying a source of vibration at a constant frequency on human tissues can provide better information (Torvinen et al., 2002).

In this study, microcontroller-based hardware which gives vibration excitation at constant frequency was designed. Then, 20 healthy volunteer subjects were identified. Vibrations were generated by a DC-motor which would provide excitation on the facial regions of the subjects. And, vibration signals were measured from 9 regions around the sinus regions by means of hardware including MEMs sensor. So, a database was created for all subjects and their frequency characteristics have been examined for 9 regions on each human face. During the analysis part of vibration signals, median and maximum frequency methods were used. 


\section{2-14 December, 2019}

\section{Barcelona, spain}

\section{Material and Method}

\subsection{Creating the Database}

Firstly, 20 healthy volunteer subjects (12 males and 8 females, between 25-35 years of age) were identified in order to create the database. The clinical examinations were performed the health of nasal cavity. Then, the vibration signals from the regions determined on the face were recorded and a database was created.

\subsection{Measurement Regions}

The measurements regions were obtained from the Frontalis muscles denoted as F (Forehead Region), regions and around the Zygomaticus minor and Zygomaticus major muscles denoted as MR (Right Cheek Region) and ML (Left Cheek Region) regions. These regions consist of 9 points in the near regions of the frontal and maxillary sinuses and each region point is away 3 $\mathrm{cm}$ from the vibration motor. These points are shown in Fig. 1 (Ak, 2019). In this figure, the measurement points are identified as F1, F2, F3, around the frontal sinus in the forehead; MR1, MR2, MR3 close to the maxillary sinuses in the right cheek, and ML1, ML2, ML3 close to the maxillary sinuses in the left cheek (Fokkens et al., 2011), (Cler et al., 2011). Also, the vibration motor points are shown as black circles.

Fig. 1. Vibration Motor and Measurement Points

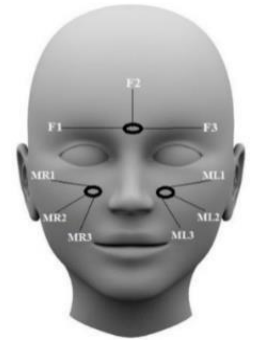

In the study, the sampling frequency of the vibration signals is determined as $350 \mathrm{~Hz}$. A microcontroller-based hardware consisting of a DC-motor unit and a sensing module at a

fixed distance $(3 \mathrm{~cm})$ to this unit for each measurement, has been designed. An interface has been developed for the communication of this equipment with the computer and the analysis of the obtained signals. The overall block diagram of the system is shown in Fig. 2 (Ak, 2019).

Fig. 2. System Block Diagram 


\section{International Conference on Research in ENGINEERING and TECHNOLOGY \\ 12-14 December, 2019 \\ Barcelona, spain}

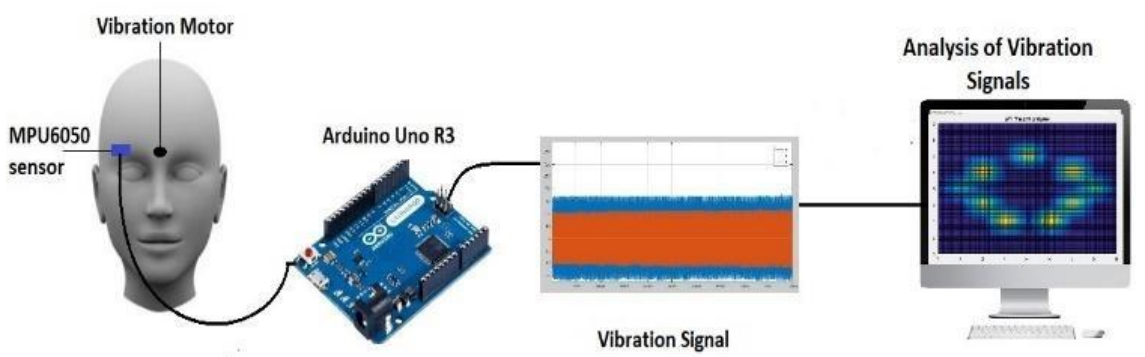

\subsection{Median and Maximum Frequency}

The vibration signals measured from the subjects were analyzed using median and maximum frequency calculations. Median frequency is defined as the median value of the frequency values of the signal. 50\% of the Power Area of the signal are below the median frequency, 50\% of the Power area values of the signal are above the median frequency. The median frequency is theoretically defined as (Eq. 1);

$$
\text { Median Frequency }=\frac{1}{2} \sum_{j=1}^{m} P j
$$

Where, $P j$ is denoted as Power spectral density values of the signal. Parameter $m$, explains length of frequency vector (Chan et al., 2016), (Phinyomark et al., 2012). The maximum frequency is the frequency magnitude value corresponding to the highest power value.

\section{Results}

In this study, median and maximum frequency values of each signals were calculated. The mean of the median frequency values of the F-MR-ML regions of the vibration signals obtained from 20 volunteer subjects is shown in Fig. 3. The median frequency values in this plot showed that $\mathrm{F}$ region is corresponded to the lowest frequency values and ML region is corresponded to highest frequency values.

The median frequency value of the $\mathrm{F}$ region is $125.78 \mathrm{~Hz}$ and the frequency range are 119.81 - $135.33 \mathrm{~Hz}$ for all subjects. The median frequency value of the MR region is $130.77 \mathrm{~Hz}$ and the frequency range are $122.72-136.85 \mathrm{~Hz}$, the median frequency value of the ML region is $132 \mathrm{~Hz}$ and the frequency range is $124.59-136.84 \mathrm{~Hz}$. 


\section{2-14 December, 2019}

\section{Barcelona, spain}

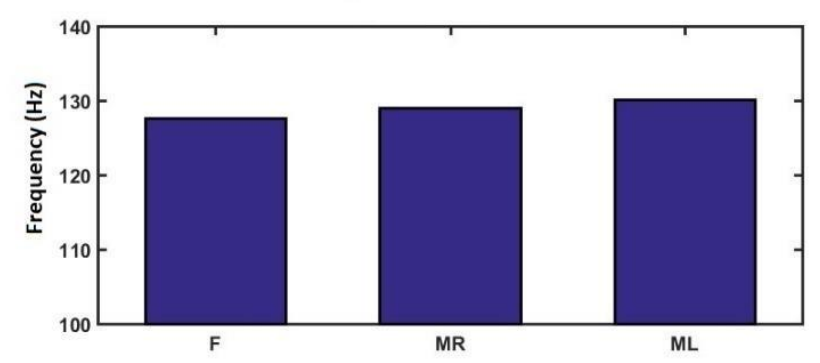

Fig. 3. Median Frequency values of F-MR-ML Regions

The maximum frequency values of the F-MR-ML regions is shown in Fig. 4. As in the median frequency, the face region having the lowest frequency values is $\mathrm{F}$ and the face region having the highest frequency values is ML.

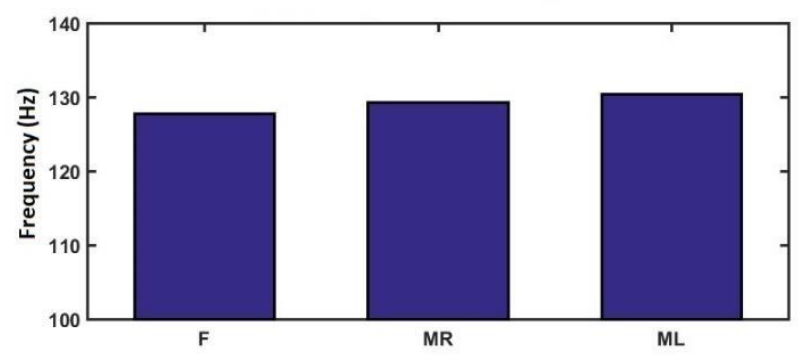

Fig. 4. Maximum Frequency values of F-MR-ML Regions

As a result, it is concluded that low frequency signals are seen in hard tissues and high frequency signals are seen in soft tissues.

\section{Conclusion and Discussion}

In this study, vibration signals were measured with MPU-6050 accelerometer sensor and transferred to the computer with the help of Arduino Uno R3. These signals are recorded with the designed computer interface and the database is obtained. The database contains vibration signals from 9 measuring points identified in the face regions of 20 volunteer subjects. Then, median and maximum frequency values were calculated.

The points in the F region were analysed and the frequency values at the F1 and F3 points were higher than the frequency values at the F2 points. The points in the MR region were analysed and the lowest frequency values were found at MR1 points and the highest frequency values were found at MR3 points. Similarly, the points in the ML region were analysed and the lowest frequency values were found at ML1 points and the highest frequency values were found at ML3 points. 


\section{International Conference on Research in ENGINEERING and TECHNOLOGY}

\section{2-14 December, 2019}

\section{Barcelona, spain}

In the literature, there are studies for the analysis of vibration signals (Desmoulin \& Anderson, 2011), (Otamendi, 2017). These studies usually include models and simulations related to vibrations generated by variable frequency audio signals. In addition, vibration signals analysis was used to diagnose diseases such as sleep apnea and nasal polyps (Morillo et al., 2010), (Orun, 2017), (Várady et al., 2010), (Rendon, 2007).

In this study differently, vibration signals obtained by applying a constant frequency source of vibration to human faces were measured and frequency characteristics were obtained. And, clearer measurements were obtained.

The results show that this model gives successful results in distinguishing the hard and soft tissues on the face. The results show that this model gives successful results in distinguishing the hard and soft tissues on the face. This model is thought to be helpful in the diagnosis of nasal diseases in future studies. Thus, it is aimed to propose a more harmless and economical method.

\section{Acknowledgment}

This study was supported by Akdeniz University Scientific Research Projects Coordination Unit with project FBA-2019-4404. In addition, with the 2012-KAEK-20 decision, Akdeniz University Faculty of Medicine Clinical Research Ethics Committee has obtained permission to conduct the study in terms of scientific and ethical issues.

\section{References}

[1] Coyte, J. L., Stirling, D., Du, H., Ros, M. (2015). 'Seated whole-body vibration analysis, technologies, and modeling: a survey.' IEEE Transactions on Systems, Man, and Cybernetics: Systems, 46(6), 725-739.

[2] H. Peter, T. Podszus \& P. von Wichert, (1987). Sleep Related Disorders and Internal Diseases. New York: Springer-Verlag. 101- 107.

[3] Zhang Z., Zhong X., Yansong H. (2009). 'Design of Measurement and Evaluation System for human exposure to mechanical vibration.' IEEE International Conference on. IEEE.

[4] Yanxi R., Qingxia L. (2010). 'Implementation of Human Vibration Test and Evaluation SystemBased on Virtual Instrument.' IEEE International Conference on. IEEE.

[5] Kitamura, T. (2012). 'Measurement of vibration velocity pattern of facial surface during phonation using scanning vibrometer.' Acoustical Science and Technology, 33(2), 126128.

[6] Balbinot, A., Marilda S. C., Diogo K. (2008) 'Zigbee network for measurement of human vibration.' Computational Science and Engineering Workshops. 11th IEEE International Conference on. IEEE.

[7] De Capua, C., Meduri, A., Morello, R. (2009) 'A hand-arm vibration meter monitoring the percussion exposure for health risk prevention applications.' In Medical Measurements and Applications. IEEE International Workshop, (45-50). 


\section{International Conference on Research in ENGINEERING and TECHNOLOGY}

\section{2-14 December, 2019}

\section{Barcelona, spain}

[8] Amar, Mohamed RS. (2010). 'Estimation of mechanical properties of soft tissue subjectedto dynamic impact'. Msc thesis, University of Nebraska.

[9] Morillo, D. S., Ojeda, J. L. R., Foix, L. F. C., Jiménez, A. L. (2010). 'An accelerometerbased device for sleep apnea screening.' IEEE transactions on information technology in biomedicine, 14(2), 491-499.

[10] Chen, F. C., Ma, E. P. M. and Yiu, E. M. L. (2014). 'Facial bone vibration in resonant voice production'. Journal of Voice, 28(5): 596-602.

[11] Orun, E. (2017). 'Analysis of The Fundamental Frequency and Nasal Sound in Patients with Nasal Polyps.' PhD thesis, Istanbul University.

[12] Kitamura, T., Hatano, H., Saitou, T., Shimokura, Y., Haneishi, E., Kishimoto, H. (2013). 'Pilot study of vibration pattern measurement for facial surface during singing by using scanning vibrometer. In Proceedings of Stockholm Music Acoustics Conference. Vol. p.4.

[13] Torvinen, S., Kannus, P., SievaÈnen, H., JaÈrvinen, T. A., Pasanen, M., Kontulainen, S., Vuori, I. (2002). 'Effect of a vibration exposure on muscular performance and body balance.' Clinical physiology and functional imaging, 22(2), 145-152.

[14] Fokkens, W. J., Lund, V. J., Mullol, J., Bachert, C., Alobid, I., Baroody, F., Georgalas, C. (2011). 'European position paper on rhinosinusitis and nasal polyps.' A summary for otorhinolaryngologists Rhinology, 50(1), 1-12.

[15] Cler, M. J., Lien, Y. A. S., Braden, M. N., Mittelman, T., Downing, K. and Stepp, C. E. (2016). 'Objective Measure of Nasal Air Emission Using Nasal Accelerometry'. Journal of Speech, Language and Hearing Research, 59(5): 1018-1024.

[16] Ak M.U. (2019) 'Investigation the Frequency Characteristics of Vibration Signals on The Human Face' MsC thesis, Akdeniz University.

[17] Tonner, P.H., Bein, B. (2006). 'Classic electroencephalographic parameters: median frequency, spectral edge frequency etc.' Best Practice \& Research Clinical Anaesthesiology, 20(1), 147-159.

[18] Chan, C. K., Timothy, G. F., \& Yeow, C. H. (2016). Comparison of mean frequency and median frequency in evaluating muscle fiber type selection in varying gait speed across healthy young adult individuals. 38th Annual International Conference of the IEEE Engineering in Medicine and Biology Society (EMBC), pp. 1725-1728.

[19] Phinyomark A., Thongpanja S., Hu H., Phukpattaranont P., Limsakul C. (2012). 'The usefulness of mean and median frequencies in electromyography analysis, in Computational Intelligence in Electromyography Analysis - A Perspective on Current Applications and Future Challenges'. p.195-220.

[20] Desmoulin, G. T., Anderson, G.S. (2011). 'Method to Investigate Contusion Mechanics in Living Humans.' J Forensic Biomech, 2:1-10. 


\section{International Conference on Research in ENGINEERING}

and TECHNOLOGY

\section{2-14 December, 2019}

\section{Barcelona, spain}

[21] Otamendi, G. (2011). 'Designing deformable models of soft tissue for virtual surgery Planning and simulation using the Mass-Spring Model.' PhD thesis, University of Navarra.

[22] P. Várady, L. Nagy, L. Szilágyi. (2000). 'On-Line Detection of Sleep Apnea during Critical Care Monitoring.' IEEE Proceedings of the 22nd Annual EMBS International Conference.

[23] Rendon, D.B. (2007). 'Mapping the human body for vibrations using an accelerometer.' Engineering in Medicine and Biology Society. EMBS. 29th Annual

International 